\title{
Synthesis and characterization of poly(tetramethylsilarylenesiloxane) derivatives bearing diphenylfluorene or diphenyldibenzosilole moieties
}

\author{
Kazutoshi Imai $^{1}$, Yoshihiko Kihara ${ }^{1}$, Atsushi Kimoto ${ }^{2}$, Jiro Abe $^{2}$, Yasufumi Tamai ${ }^{1}$ and Nobukatsu Nemoto ${ }^{1}$ \\ Poly(tetramethylsilarylenesiloxane) derivatives having diphenylfluorene (P1) or diphenyldibenzosilole (P2) moieties were \\ prepared via polycondensation of the corresponding disilanol monomers, that is, 2,7-bis(dimethylhydroxysilyl)-9,9- \\ diphenylfluorene (M1) and 2,7-bis(dimethylhydroxysilyl)-9,9-diphenyldibenzosilole (M2), respectively. P1 and P2 exhibited good \\ solubility in common organic solvents. The glass transition temperatures $\left(T_{\mathrm{g}} \mathrm{s}\right)$ of P1 and P2 were determined by differential \\ scanning calorimetry to be 125 and $119{ }^{\circ} \mathrm{C}$, respectively. The melting temperature $\left(T_{\mathrm{m}}\right)$ of $\mathrm{P} 1$ was observed at $276^{\circ} \mathrm{C}$; however, \\ the $T_{\mathrm{m}}$ of $\mathrm{P} 2$ was not observed, indicating that the introduction of a dibenzosilole moiety decreased the crystallization tendency. \\ The temperatures at $5 \%$ weight loss $\left(T_{\mathrm{d} 5} \mathrm{~s}\right)$ of $\mathrm{P} 1$ and $\mathrm{P} 2$ were 539 and $520^{\circ} \mathrm{C}$, respectively, suggesting good thermostability of \\ $P 1$ and P2. Bathochromic and hyperchromic effects were observed in the absorption and fluorescence spectra by introducing a \\ dimethylsilyl substituent onto diphenylfluorene and diphenyldibenzosilole skeletons. The replacement of diphenylfluorene by the \\ corresponding diphenyldibenzosilole also led to bathochromic shifts. The fluorescence quantum yield $\left(\Phi_{F}\right)$ of $P 1$ was lower than \\ that of $\mathrm{M} 1$, probably because of the formation of aggregates; however, the $\Phi_{\mathrm{F}}$ of $\mathrm{P} 2$ was higher than that of $\mathrm{M} 2$, indicating \\ a decrease in the tendency toward aggregation using a dibenzosilole skeleton.
}

Polymer Journal (2011) 43, 58-65; doi:10.1038/pj.2010.104; published online 3 November 2010

Keywords: dibenzosilole; fluorene; heat-resistant polymer; photoluminescence; polysiloxane; poly(tetramethylsilarylenesiloxane)

\section{INTRODUCTION}

Fluorene derivatives have been very attractive molecules suitable for applications in electronics and optoelectronics, such as organic light emitting diodes (OLEDs). Fluorene-based conjugated polymers are also promising candidates for blue-light-emitting polymers because they have exhibited excellent quantum efficiencies in photoluminescence, as well as chemical and thermal stabilities. ${ }^{1-4}$ High thermal and oxidative stabilities are also required for blue-light-emitting polymers because blue-light emissions are associated with high energy gaps and high-electrical field intensities; however, the 9-position of fluorenyl moiety is easily oxidized at high operating temperature, inducing the decline of the color stability of light emission resulting from changes in the emission spectra. ${ }^{5-7}$ The introduction of bulky aryl moieties into the 9-position of fluorene has been reported to be effective in the inhibition of oxidation, although the low solubilities in common organic solvents raise another problem owing to the increase in the tendency to crystallize. ${ }^{8}$

On the other hand, conjugated polymers based on dibenzosilole, in which the vulnerable C-9 carbon in fluorene is replaced by a silicon, have been reported to be new polymeric materials for OLEDs in recent years. ${ }^{9,10}$ Dibenzosilole-based conjugated polymers have also been reported to be difficult to oxidize at high operating temperature. ${ }^{9}$ The enhancement of electron affinity owing to the $\sigma^{*}-\pi^{*}$ conjugation as observed in analogous molecular and polymeric siloles ${ }^{11}$ may also attract interest in dibenzosilole-based conjugated polymers.

In the meantime, the incorporation of a silyl substituent onto aromatic species has been reported to result in high fluorescence quantum yield. ${ }^{12-17}$ Kitamura et al. ${ }^{18}$ reported a polysiloxane having fluorenyl moiety in the main chain; however, the obtained polysiloxane derivative was an oil product owing to the extremely low glass transition temperature $\left(T_{\mathrm{g}}\right)$. Thus, the use of polysiloxane derivatives as polymeric OLED materials seems to be inadequate because of their extremely low $T_{\mathrm{g}},{ }^{19,20}$ which allows the formation of aggregates and/or interchain excimers to induce the decline of the color stability of light emission. ${ }^{5-7}$ This is so even though the other properties of polysiloxanes such as good thermostability and stability against atomic oxygen, ${ }^{19}$ which is generated by the irradiation of ultraviolet light to molecular oxygen $\left(\mathrm{O}_{2}\right)$, would be appropriate for polymeric OLED materials. To raise $T_{\mathrm{g}}$, we achieved the synthesis of fluorene-based polysiloxane derivatives with a bulky spirofluorenyl substituent on the

${ }^{1}$ Department of Chemical Biology and Applied Chemistry, College of Engineering, Nihon University, Tamura-machi, Fukushima, Japan and ${ }^{2}$ Department of Chemistry, School of Science and Engineering, Aoyama Gakuin University, Fuchinobe, Chuo-ku, Kanagawa, Japan

Correspondence: Professor N Nemoto, Department of Chemical Biology and Applied Chemistry, College of Engineering, Nihon University, Tamura-machi, Koriyama, Fukushima 963-8642, Japan.

E-mail: nemoto@chem.ce.nihon-u.ac.jp

Received 9 August 2010; revised and accepted 19 September 2010; published online 3 November 2010 


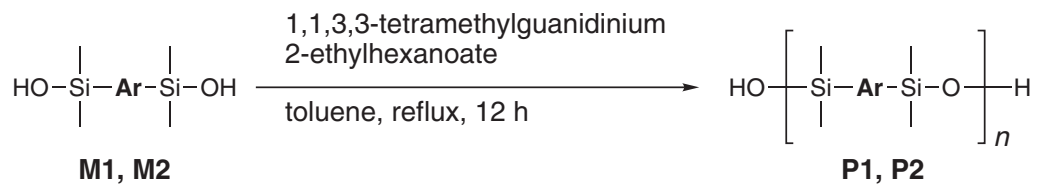

Ar:
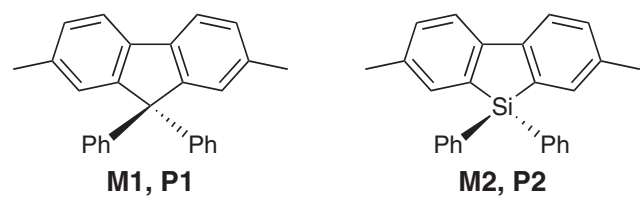

Scheme 1 Polycondensation of 2,7-bis(dimethylhydroxysilyl)-9,9-diphenylfluorene (M1) and 2,7-bis(dimethylhydroxysilyl)-9,9-diphenyldibenzosilole (M2).

C-9 carbon. ${ }^{21}$ The obtained polysiloxane derivative exhibited a $T_{\mathrm{g}}$ of $156^{\circ} \mathrm{C}$, indicating that the fluorene-based polysiloxanes with high $T_{\mathrm{g}}$ can be obtained by the introduction of bulky and rigid substituents onto the C-9 carbon of fluorene.

In this article, we report the synthesis of novel poly(tetramethylsilarylenesiloxane) derivatives with fluorene or dibenzosilole moieties, at the 9-position of which the bulky phenyl substituents were attached, as shown in Scheme 1. The effects of the introduction of dibenzosilole moiety into poly(tetramethylsilarylenesiloxane) derivatives on the thermal and optical properties will also be discussed.

\section{EXPERIMENTAL PROCEDURE}

\section{Materials}

9,9-Diphenylfluorene (1) (Wong et al..$^{22}$ ) and 4,4'-dibromo-2,2'-diiodobiphenyl (4) (Chan et al..$^{9}$ ) were prepared by the method reported in the literature. Dichlorodiphenylsilane, chlorodimethylsilane (Acros organics, Geel, Belgium), $1.6 \mathrm{moll}^{-1} t$-butyllithium in pentane, magnesium, bromine, sodium, sodium carbonate, potassium dihydrogenphosphate (KANTO KAGAKU, Tokyo, Japan) and 5\% palladium on charcoal (Escat 103, from Aldrich, St Louis, MO, USA) were commercially available and used as received. The catalyst 1,1,3,3-tetramethylguanidinium 2-ethylhexanoate was prepared according to the literature. ${ }^{23}$ Ethanol was used after distillation over magnesium ethoxide. Toluene and tetrahydrofuran (THF) were used after distillation over sodium. Chloroform was used after distillation over calcium hydride.

\section{Measurements}

${ }^{1} \mathrm{H}$ and ${ }^{13} \mathrm{C}$ nuclear magnetic resonance (NMR) spectra were recorded on a Bruker AVANCE 400F spectrometer (Bruker, Karlsruhe, Germany) in deuterated chloroform $\left(\mathrm{CDCl}_{3}\right)$ or dimethylsulfoxide $\left(\left(\mathrm{CD}_{3}\right)_{2} \mathrm{SO}\right)$ at ambient temperature. Infrared (IR) spectra were measured on a PerkinElmer Spectrum One FT-IR spectrometer (PerkinElmer, Waltham, MA, USA). Melting point $\left(T_{\mathrm{m}}\right)$ and glass transition temperature $\left(T_{\mathrm{g}}\right)$ were determined by differential scanning calorimetry (DSC) on a RIGAKU ThermoPlus DSC 8230 (Rigaku Co., Inc., Tokyo, Japan) at a heating rate of $10{ }^{\circ} \mathrm{C} \mathrm{min}^{-1}$ under a nitrogen flow rate of $10 \mathrm{ml} \mathrm{min}^{-1}$. Thermogravimetry was performed on a RIGAKU ThermoPlus TG8110 at a heating rate of $10{ }^{\circ} \mathrm{Cmin}^{-1}$ under a nitrogen atmosphere. Number-average $\left(M_{\mathrm{n}}\right)$ and weight-average $\left(M_{\mathrm{w}}\right)$ molecular weights were estimated by size-exclusion chromatography on a SHOWA DENKO Shodex GPC-101 system (SHOWA DENKO K. K., Tokyo, Japan) with polystyrene gel columns (a pair of Shodex GPC LF-804), eluted with THF using a calibration curve of polystyrene standards. The purity of all prepared compounds with low-molecular weight was confirmed to be over $99 \%$ by gas chromatography (GC) analysis. Absorption and fluorescence spectra were measured on a SHIMADZU UV-2450 (Shimadzu Co., Kyoto, Japan) and a JASCO FP-6500 spectrofluorometer (JASCO Co., Tokyo, Japan), respectively, using chloroform solutions degassed by argon bubbling for $30 \mathrm{~min}$ with a fixed concentration of $4.0 \times 10^{-6} \mathrm{moll}^{-1}$ for the diphenylfluorene or diphenyldibenzosilole unit. Fluorescence quantum yields were measured using a HAMAMATSU PHOTONICS C9920-02 absolute PL quantum yield measurement system (Hamamatsu Photonics K. K., Hamamatsu, Japan). ${ }^{24}$

\section{Monomer synthesis}

2,7-Dibromo-9,9-diphenylfluorene (2). An aqueous solution $(125 \mathrm{ml})$ of sodium carbonate $(1.31 \mathrm{~g}, 12.4 \mathrm{mmol})$ was added to the chloroform solution $(200 \mathrm{ml})$ of $1(7.88 \mathrm{~g}, 24.7 \mathrm{mmol})$ at $5^{\circ} \mathrm{C}$. Iodine $(0.15 \mathrm{~g}, 0.6 \mathrm{mmol})$ and bromine $(9.36 \mathrm{~g}, 58.6 \mathrm{mmol})$ were added to this mixture at $5^{\circ} \mathrm{C}$, and the resulting mixture was stirred for $12 \mathrm{~h}$ at ambient temperature. In addition, bromine $(9.36 \mathrm{~g}, 58.6 \mathrm{mmol})$ was added to the reaction mixture at $5{ }^{\circ} \mathrm{C}$, and the resulting mixture was stirred for $12 \mathrm{~h}$ at ambient temperature. Then, an aqueous solution $(50 \mathrm{ml})$ of sodium hydroxide $(4.68 \mathrm{~g}, 117.1 \mathrm{mmol})$ was added to the reaction mixture. This was stirred for $30 \mathrm{~min}$ and poured into a mixture of sodium thiosulfate aqueous solution and chloroform. The crude product was extracted with chloroform, and the resulting chloroform solution was washed with saturated sodium hydrogen carbonate aqueous solution, dried over anhydrous magnesium sulfate and filtered. The filtrate was concentrated under reduced pressure, and the crude product was recrystallized from toluene to afford 2 as a colorless solid with a yield of $10.62 \mathrm{~g}(90 \%)$.

${ }^{1} \mathrm{H}$ NMR $\left(\mathrm{CDCl}_{3}, 400 \mathrm{MHz}\right): \delta$ (p.p.m. $)=7.59(\mathrm{~d}, J=7.9 \mathrm{~Hz}, 2 \mathrm{H}$, fluorenyl protons), 7.49 (s, $2 \mathrm{H}$, fluorenyl protons), 7.48 (d, $J=7.9 \mathrm{~Hz}, 2 \mathrm{H}$, fluorenyl protons), 7.24-7.27 ( $\mathrm{m}, 6 \mathrm{H}$, phenyl protons), 7.13-7.18 (m, $4 \mathrm{H}$, phenyl protons). ${ }^{13} \mathrm{C}$ NMR $\left(\mathrm{CDCl}_{3}, 100 \mathrm{MHz}\right): \delta$ (p.p.m. $)=152.9,144.4,138.1$, $130.9,129.4,128.5,128.0,127.2,121.8,121.6,65.6 . \mathrm{Mp}: 278^{\circ} \mathrm{C}$ (literature ${ }^{22}$ : $\left.279^{\circ} \mathrm{C}\right)$.

2,7-Dibromo-9,9-diphenyldibenzosilole (5). Under a dry argon atmosphere, $13.30 \mathrm{ml}(21.2 \mathrm{mmol})$ of $1.6 \mathrm{moll}^{-1} t$-butyllithium in heptane was added drop wise to the THF solution $(60 \mathrm{ml})$ of $4(3.0 \mathrm{~g}, 5.32 \mathrm{mmol})$ over $2 \mathrm{~h}$ at $-78^{\circ} \mathrm{C}$. After the reaction mixture was stirred for $1 \mathrm{~h}$, dichlorodiphenylsilane $(2.70 \mathrm{~g}$, $10.64 \mathrm{mmol}$ ) was added to the mixture at $-78^{\circ} \mathrm{C}$. After the reaction mixture was stirred for $12 \mathrm{~h}$ at ambient temperature, it was poured into $100 \mathrm{ml}$ of $0.1 \mathrm{moll}^{-1} \mathrm{HCl}$ and the crude product was extracted with ethyl acetate. The organic layer was washed with saturated sodium hydrogen carbonate aqueous solution and brine, dried over anhydrous magnesium sulfate and filtered. The filtrate was concentrated under reduced pressure, and the crude product was purified by silica gel column chromatography eluted with the mixed solvent of hexane/chloroform $(\mathrm{v} / \mathrm{v}=10 / 1)$. The fraction with an $\mathrm{R}_{\mathrm{f}}$ value of 0.43 was collected and concentrated under reduced pressure. The residue was recrystallized from methanol to afford $\mathbf{5}$ as a colorless plate with a yield of $1.84 \mathrm{~g}(70 \%)$.

${ }^{1} \mathrm{H} \mathrm{NMR}\left(\mathrm{CDCl}_{3}, 400 \mathrm{MHz}\right): \delta$ (p.p.m. $)=7.76(\mathrm{~d}, J=2.0 \mathrm{~Hz}, 2 \mathrm{H}$, dibenzosilolyl protons), 7.63 (d, $J=8.2 \mathrm{~Hz}, 2 \mathrm{H}$, dibenzosilolyl protons), $7.51-7.54$ (m, $6 \mathrm{H}$, phenyl protons), 7.38 (dd, $J=2.0,8.2 \mathrm{~Hz} 2 \mathrm{H}$, dibenzosilolyl protons), 7.29-7.37 (m, $4 \mathrm{H}$, phenyl protons). ${ }^{13} \mathrm{C} \mathrm{NMR}\left(\mathrm{CDCl}_{3}, 100 \mathrm{MHz}\right): \delta$ (p.p.m. $)=$ $146.4,138.5,136.6,135.5,133.8,130.9,130.7,128.4,122.8,122.7 . \mathrm{Mp}: 238^{\circ} \mathrm{C}$.

2,7-Bis(dimethylsilyl)-9,9-dipheylfluorene (3). Under a dry argon atmosphere, a THF solution $(140 \mathrm{ml})$ of $2(12.9 \mathrm{~g}, 27.2 \mathrm{mmol})$ and chlorodimethylsilane $(6.46 \mathrm{~g}, 67.9 \mathrm{mmol})$ was added drop wise to magnesium $(1.49 \mathrm{~g}, 61.1 \mathrm{mmol})$ in THF $(180 \mathrm{ml})$ at $60^{\circ} \mathrm{C}$. The reaction mixture was stirred for $12 \mathrm{~h}$ at $60^{\circ} \mathrm{C}$ and poured into the mixture of ethyl acetate $(250 \mathrm{ml})$ and $0.5 \mathrm{moll}^{-1} \mathrm{HCl}$ aqueous solution $(250 \mathrm{ml})$. The organic layer was washed successively with saturated sodium hydrogen carbonate aqueous solution and brine. The resulting ethyl acetate solution was dried over anhydrous magnesium sulfate and filtered. The 
filtrate was concentrated under reduced pressure. The residue was purified by silica gel column chromatography eluted with hexane. The fraction with an $\mathrm{R}_{\mathrm{f}}$ value of 0.48 was corrected and concentrated under reduced pressure. The crude product was recrystallized from methanol to afford $\mathbf{3}$ as a colorless plate with a yield of $8.29 \mathrm{~g}(70 \%)$.

${ }^{1} \mathrm{H}$ NMR $\left(\mathrm{CDCl}_{3}, 400 \mathrm{MHz}\right): \delta$ (p.p.m. $)=7.77(\mathrm{~d}, J=7.5 \mathrm{~Hz}, 2 \mathrm{H}$, fluorenyl protons), 7.57 (s, $2 \mathrm{H}$, fluorenyl protons), 7.53 (d, $J=7.5 \mathrm{~Hz}, 2 \mathrm{H}$, fluorenyl protons), $7.19-7.25$ (m, 10H, phenyl protons), 4.40 (sept, $J=3.7 \mathrm{~Hz}, 2 \mathrm{H}$, $\left.-\mathrm{Si}\left(\mathrm{CH}_{3}\right)_{2}-\underline{\mathrm{H}}\right), 0.31\left(\mathrm{~d}, J=3.7 \mathrm{~Hz}, 12 \mathrm{H},-\mathrm{Si}\left(\mathrm{CH}_{3}\right)_{2}-\mathrm{H}\right) .{ }^{13} \mathrm{C} \mathrm{NMR}\left(\mathrm{CDCl}_{3}\right.$, $100 \mathrm{MHz}$ ): $\bar{\delta}$ (p.p.m.) $=150.5,146.0,141.1,137 . \overline{2}, 133.1,131.8,128.2,128.1$, 126.5, 119.7, 65.5, -3.6. IR $\left(\mathrm{KBr}, \mathrm{cm}^{-1}\right): 2122(\mathrm{Si}-\mathrm{H}) . \mathrm{Mp}: 195^{\circ} \mathrm{C}$.

2,7-Bis(dimethylsilyl)-9,9-diphenyldibenzosilole (6). The silole 6 was prepared by a method similar to that used in the preparation of $\mathbf{3}$, using $\mathbf{5}$ as the raw material. Yield: $13.76 \mathrm{~g}(74 \%)$ obtained as a colorless plate.

${ }^{1} \mathrm{H}$ NMR $\left(\mathrm{CDCl}_{3}, 400 \mathrm{MHz}\right): \delta$ (p.p.m. $)=7.94$ (s, $2 \mathrm{H}$, dibenzosilolyl protons), 7.89 (d, $J=7.6 \mathrm{~Hz}, 2 \mathrm{H}$, dibenzosilolyl protons), 7.65-7.66 ( $\mathrm{m}, 6 \mathrm{H}$, phenyl protons), 7.37 (d, $J=7.6 \mathrm{~Hz}, 2 \mathrm{H}$, dibenzosilolyl protons), $7.34-7.38(\mathrm{~m}, 4 \mathrm{H}$, phenyl protons), 4.45 (sept, $\left.J=3.7 \mathrm{~Hz}, 2 \mathrm{H},-\mathrm{Si}\left(\mathrm{CH}_{3}\right)_{2}-\mathrm{H}\right), 0.36(\mathrm{~d}, J=3.7 \mathrm{~Hz}$, $\left.12 \mathrm{H},-\mathrm{Si}\left(\mathrm{CH}_{3}\right)_{2}-\mathrm{H}\right) .{ }^{13} \mathrm{C} \mathrm{NMR}\left(\mathrm{CDCl}_{3}, 100 \mathrm{MHz}\right): \delta$ (p.p.m. $)=149.6,139.6$, 137.1, 136.5, 135.6, 135.3, 132.7, 130.1, 128.1, 120.7, -3.66. IR $\left(\mathrm{KBr}, \mathrm{cm}^{-1}\right)$ : 2124 (Si-H). Mp: $121^{\circ} \mathrm{C}$.
2,7-Bis(dimethylhydroxysilyl)-9,9-diphenylfluorene (M1). A THF solution $(50 \mathrm{ml})$ of 2,7-bis(dimethylsilyl)-9,9-diphenylfluorene $(3,6.01 \mathrm{~g}, 13.8 \mathrm{mmol})$ was added to a mixture of $0.05 \mathrm{~g}$ of $5 \%$ palladium on charcoal in THF $(30 \mathrm{ml})$ and water $(0.67 \mathrm{~g}, 38.5 \mathrm{mmol})$ at room temperature. After the reaction mixture was stirred for $4 \mathrm{~h}$, it was filtered using celite. The filtrate was concentrated under reduced pressure. The crude product was recrystallized from toluene to afford M1 as a colorless solid with a yield of $5.68 \mathrm{~g}(88 \%)$.

${ }^{1} \mathrm{H} \mathrm{NMR}\left(\left(\mathrm{CD}_{3}\right)_{2} \mathrm{SO}, 400 \mathrm{MHz}\right): \delta$ (p.p.m. $)=7.91(\mathrm{~d}, J=7.5 \mathrm{~Hz}, 2 \mathrm{H}$, fluorenyl protons), $7.60(\mathrm{~s}, 2 \mathrm{H}$, fluorenyl protons), $7.56(\mathrm{~d}, J=7.5 \mathrm{~Hz}, 2 \mathrm{H}$, fluorenyl protons), 7.28-7.21 ( $\mathrm{m}, 6 \mathrm{H}$, phenyl protons), 7.09-7.11 ( $\mathrm{m}, 4 \mathrm{H}$, phenyl protons), $5.91\left(\mathrm{~s}, 2 \mathrm{H},-\mathrm{Si}\left(\mathrm{CH}_{3}\right)_{2}-\mathrm{OH}\right), 0.20\left(\mathrm{~s}, 12 \mathrm{H},-\mathrm{Si}\left(\mathrm{CH}_{3}\right)_{2}-\mathrm{OH}\right) .{ }^{13} \mathrm{C} \quad \mathrm{NMR}$ $\left(\left(\mathrm{CD}_{3}\right)_{2} \mathrm{SO}, 100 \mathrm{MHz}\right): \delta$ (p.p.m. $)=149.7,145.6,140.5,132.2,130.2,128.3$, $128.2,127.5,126.5,119.8,64.9,0.6$. IR $\left(\mathrm{KBr}, \mathrm{cm}^{-1}\right)$ : $3401(-\mathrm{OH}) . \mathrm{Mp}$ : $209^{\circ}$ C. Anal. Calcd for $\mathrm{C}_{29} \mathrm{H}_{30} \mathrm{O}_{2} \mathrm{Si}_{2}$ : C, 74.63; H, 6.48. Found: C, 74.63; H, 6.50.

2,7-Bis(dimethylhydroxysilyl)-9,9-diphenyldibenzosilole (M2). Under a dry argon atmosphere, sodium $(0.5 \mathrm{~g})$ was added to $15 \mathrm{ml}$ of ethanol at room temperature. To the resulting clear solution $6(2.32 \mathrm{~g}, 5.15 \mathrm{mmol})$ was added in ethanol $(30 \mathrm{ml})$. After the reaction mixture was refluxed for $2 \mathrm{~h}$, a solution of sodium hydroxide $(0.75 \mathrm{~g}, 18.75 \mathrm{mmol})$ in a mixture of water $(0.5 \mathrm{ml})$ and methanol $(3.75 \mathrm{ml})$ was added to the solution, and the reaction mixture was stirred for $15 \mathrm{~min}$. After the reaction mixture was poured into an aqueous solution $(50 \mathrm{ml})$ of potassium dihydrogen phosphate $(5.50 \mathrm{~g}, 40.41 \mathrm{mmol})$ in

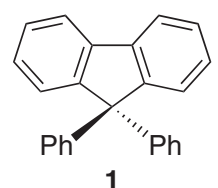

$\mathrm{Na}_{2} \mathrm{CO}_{3}$ aq., $\mathrm{I}_{2}, \mathrm{Br}_{2}, \mathrm{CHCl}_{3}, 5^{\circ} \mathrm{C}$

r.t., $12 \mathrm{~h}$

1<smiles>Brc1ccc2c(c1)C(c1ccccc1)(c1ccccc1)c1cc(Br)ccc1-2</smiles>

2<smiles>C[Si](C)(C)c1ccc2c(c1)C(c1ccccc1)(c1ccccc1)c1cc([Si](C)(C)C)ccc1-2</smiles>

3<smiles>[M]C1(c2ccccc2)c2cc([Si](C)(C)O)ccc2-c2ccc([Si](C)(C)O)cc21</smiles>

Scheme 2 Synthetic pathways for 2,7-bis(dimethylhydroxysilyl)-9,9-diphenylfluorene (M1).<smiles>Brc1ccc(-c2ccc(Br)cc2I)c(I)c1</smiles>

t-BuLi / THF, $-78^{\circ} \mathrm{C}, 1 \mathrm{~h}$
$\mathrm{Ph}_{2} \mathrm{SiCl}_{2}$, r.t., $12 \mathrm{~h}$

$\underset{\text { reflux, } 12 \mathrm{~h}}{\stackrel{\mathrm{Mg}, \mathrm{HSi}\left(\mathrm{CH}_{3}\right)_{2} \mathrm{Cl} / \mathrm{THF}}{\longrightarrow}}$<smiles>Brc1ccc2c(c1)[Si](c1ccccc1)(c1ccccc1)c1cc(Br)ccc1-2</smiles>

5<smiles>C[Si](C)(C)c1ccc2c(c1)[Si](c1ccccc1)(c1ccccc1)c1cc([Si](C)(C)C)ccc1-2</smiles>

6

i) EtONa / EtOH, reflux, $2 \mathrm{~h}$

ii) $\mathrm{NaOH} / \mathrm{MeOH}, \mathrm{H}_{2} \mathrm{O}$, r.t., $15 \mathrm{~min}$

iii) $\mathrm{KH}_{2} \mathrm{PO}_{4}$ aq., $0^{\circ} \mathrm{C}, 30 \mathrm{~min}$<smiles>C[Si](C)(O)c1ccc2c(c1)[Si](c1ccccc1)(c1ccccc1)c1cc([Si](C)(C)O)ccc1-2</smiles>

M2

Scheme 3 Synthetic pathways for 2,7-bis(dimethylhydroxysilyl)-9,9-diphenyldibenzosilole (M2). 
an ice bath, it was stirred for $30 \mathrm{~min}$. The crude product was extracted with ethyl acetate, dried over anhydrous magnesium sulfate and filtered. The filtrate was concentrated under reduced pressure. The crude product was recrystallized from the mixed solvent of toluene and hexane to afford M2 as a colorless powder with a yield of $1.98 \mathrm{~g}(80 \%)$.

${ }^{1} \mathrm{H}$ NMR $\left(\left(\mathrm{CD}_{3}\right)_{2} \mathrm{SO}, 400 \mathrm{MHz}\right): \delta$ (p.p.m. $)=8.03 \quad(\mathrm{~s}, 2 \mathrm{H}$, dibenzosilolyl protons), 8.02 (d, $J=7.5 \mathrm{~Hz}, 2 \mathrm{H}$, dibenzosilolyl protons), $7.70(\mathrm{~d}, J=7.5 \mathrm{~Hz}, 2 \mathrm{H}$, dibenzosilolyl protons), $7.60(\mathrm{~d}, J=8.2 \mathrm{~Hz}, 4 \mathrm{H}$, phenyl protons), 7.46-7.39 (m, $6 \mathrm{H}$, phenyl protons), $5.94\left(\mathrm{~s}, 2 \mathrm{H},-\mathrm{Si}\left(\mathrm{CH}_{3}\right)_{2}-\mathrm{OH}\right), 0.27\left(\mathrm{~s}, 12 \mathrm{H},-\mathrm{Si}\left(\mathrm{CH}_{3}\right)_{2}-\right.$

Table 1 Results of polycondensation and thermal properties of the obtained polymers

\begin{tabular}{lcccccc}
\hline Polymer & Yield (\%) & $\mathrm{M}_{n}^{\mathrm{b}}$ & $\mathrm{M}_{w} / \mathrm{M}_{n}{ }^{\mathrm{c}}$ & $\mathrm{T}_{g}\left({ }^{\circ} \mathrm{C}\right)^{\mathrm{d}}$ & $\mathrm{T}_{m}\left({ }^{\circ} \mathrm{C}\right)^{\mathrm{e}}$ & $\mathrm{T}_{d 5}\left({ }^{\circ} \mathrm{C}\right)^{f}$ \\
\hline P1 & 73 & 67000 & 1.56 & 125 & 276 & 539 \\
P2 & 90 & 52000 & 2.36 & 119 & $-\mathrm{g}$ & 520 \\
\hline
\end{tabular}

Abbreviations: P1, poly(tetramethyl-9,9-diphenyl-2,7-silfluorenylenesiloxane); P2, poly(tetramethyl9,9-diphenyl-2,7-sildibenzosilolylenesiloxane).

alnsoluble part in methanol.

bNumber-average molecular weight estimated from size-exclusion chromatography eluted with tetrahydrofuran based on polystyrene standards.

cPolydispersity index.

Glass transition temperature determined by differential scanning calorimetry (DSC) at a heating rate of $10^{\circ} \mathrm{C} \mathrm{min}^{-1}$ under a nitrogen atmosphere.

${ }^{e}$ Melting temperature determined by DSC at a heating rate of $10^{\circ} \mathrm{C} \mathrm{min}^{-1}$ under a nitrogen atmosphere.

fTemperature at $5 \%$ weight loss determined by thermogravimetry at a heating rate of

$10^{\circ} \mathrm{Cmin}^{-1}$ under a nitrogen atmosphere.

gNot observed from -50 to $400^{\circ} \mathrm{C}$.
$\mathrm{OH}) .{ }^{13} \mathrm{C}$ NMR $\left(\left(\mathrm{CD}_{3}\right)_{2} \mathrm{SO}, 100 \mathrm{MHz}\right): \delta$ (p.p.m. $)=149.1,140.8,138.6$, $136.0,135.2,134.4,132.5,130.5,128.6,121.0,0.91$. IR $\left(\mathrm{KBr}, \mathrm{cm}^{-1}\right): 3367$ (-OH). Mp: $188^{\circ}$ C. Anal. Calcd for $\mathrm{C}_{28} \mathrm{H}_{30} \mathrm{O}_{2} \mathrm{Si}_{3}$ : C, 69.66; H, 6.26. Found: C, 69.43; H, 6.57 .

\section{Polymerization procedure}

Synthesis of poly(tetramethyl-9,9-diphenyl-2,7-silfluorenylenesiloxane) (P1). The catalyst 1,1,3,3-tetramethylguanidinium 2-ethylhexanoate $(0.09 \mathrm{~g})$ was added to M1 $(0.957 \mathrm{~g}, 1.98 \mathrm{mmol})$ dissolved in toluene $(43.5 \mathrm{ml})$ and the reaction mixture was refluxed for $12 \mathrm{~h}$. The reaction mixture was filtered and poured into $900 \mathrm{ml}$ of methanol to isolate the corresponding polymer as white precipitates. Yield: $0.67 \mathrm{~g}(73 \%)$ as a white solid.

${ }^{1} \mathrm{H} \mathrm{NMR}\left(\mathrm{CDCl}_{3}, 400 \mathrm{MHz}\right): \delta$ (p.p.m. $)=7.62(\mathrm{~d}, J=7.5 \mathrm{~Hz}, 2 \mathrm{H}$, fluorenyl protons), 7.57 ( $\mathrm{s}, 2 \mathrm{H}$, fluorenyl protons), 7.41 (d, $J=7.5 \mathrm{~Hz}, 2 \mathrm{H}$, fluorenyl protons), 7.17-7.11 (m, 10H, phenyl protons), $0.17\left(\mathrm{~s}, 12 \mathrm{H},-\mathrm{Si}\left(\mathrm{CH}_{3}\right)_{2}-\right) .{ }^{13} \mathrm{C}$ $\operatorname{NMR}\left(\mathrm{CDCl}_{3}, 100 \mathrm{MHz}\right): \delta$ (p.p.m. $)=150.4,146.1,141.1,139.6,132.1,130.8$ $128.1,127.4,126.5,119.6,65.6,0.8$. IR $\left(\mathrm{KBr}, \mathrm{cm}^{-1}\right)$ : 1000-1100 (Si-O).

Synthesis of poly(tetramethyl-9,9-diphenyl-2,7-sildibenzosilolylenesiloxane) (P2). P2 was prepared by a method similar to that used in the preparation of P1 using M2 as the monomer. Yield: $0.26 \mathrm{~g}(90 \%$, obtained from $0.319 \mathrm{~g}(0.66 \mathrm{mmol})$ of M2).

${ }^{1} \mathrm{H}$ NMR $\left(\mathrm{CDCl}_{3}, 400 \mathrm{MHz}\right): \delta$ (p.p.m. $)=7.96(\mathrm{~s}, 2 \mathrm{H}$, dibenzosilolyl protons), 7.76 (d, $J=7.5 \mathrm{~Hz}, 2 \mathrm{H}$, dibenzosilolyl protons), $7.62(\mathrm{~d}, J=8.0 \mathrm{~Hz}, 6 \mathrm{H}$, phenyl protons), 7.34 (d, $J=7.5 \mathrm{~Hz}, 2 \mathrm{H}$, dibenzosilolyl protons), $7.27-7.29$ (m, $4 \mathrm{H}$, phenyl protons), $0.31\left(\mathrm{~s}, 12 \mathrm{H},-\mathrm{Si}\left(\mathrm{CH}_{3}\right)_{2-}\right) .{ }^{13} \mathrm{C} \mathrm{NMR}\left(\mathrm{CDCl}_{3}, 100 \mathrm{MHz}\right)$ : $\delta$ (p.p.m.) $=149.7,139.4,138.6,135.6,135.5,135.2,132.8,130.0,128.1,120.6$, 0.96. IR $\left(\mathrm{KBr}, \mathrm{cm}^{-1}\right): 1000-1100(\mathrm{Si}-\mathrm{O})$. a

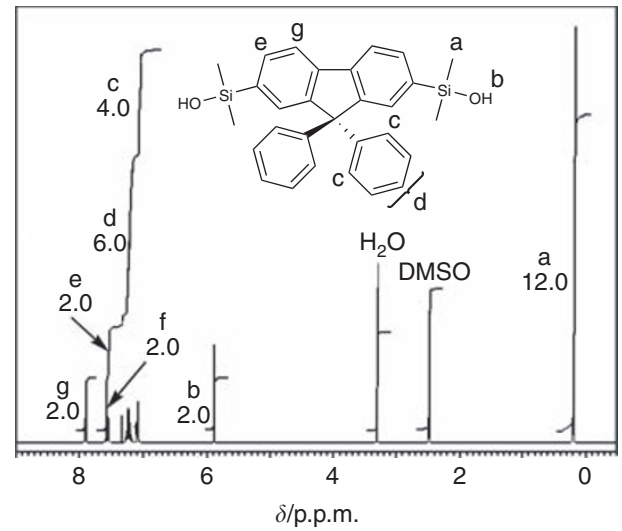

C

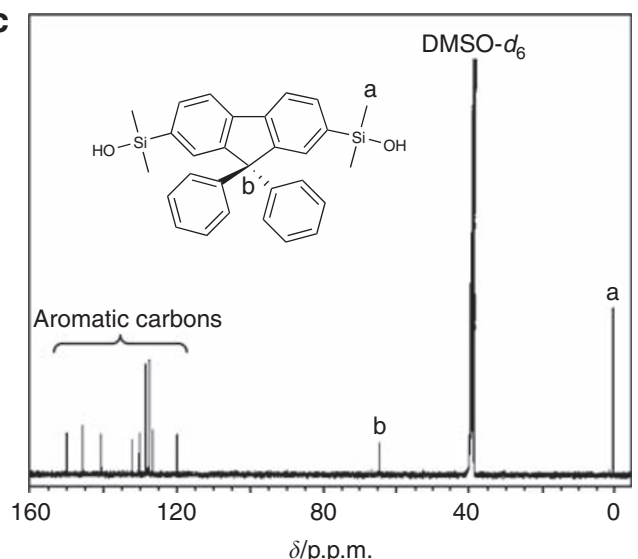

b

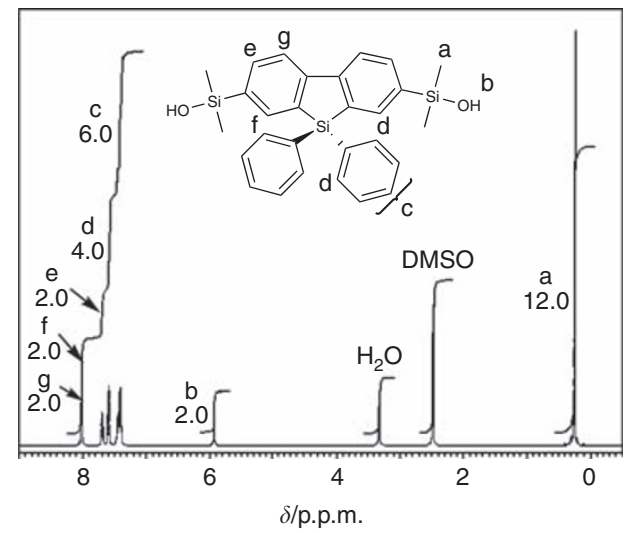

d

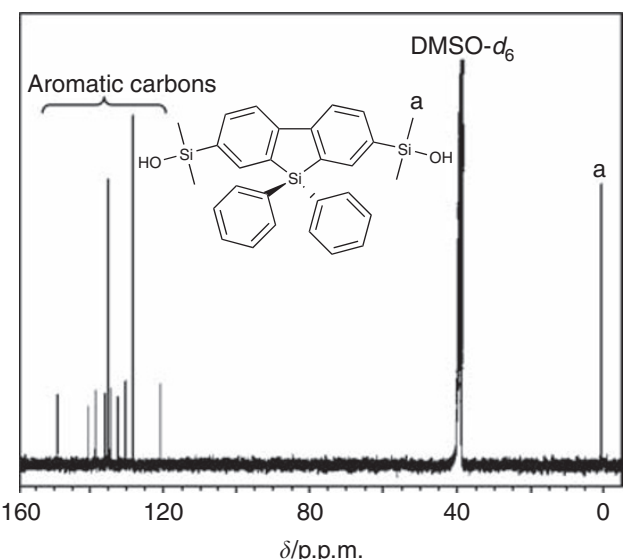

Figure $1^{1} \mathrm{H}$ nuclear magnetic resonance (NMR; $400 \mathrm{MHz}$ ) spectra of (a) 2,7-bis(dimethylhydroxysilyl)-9,9-diphenylfluorene (M1) and (b) 2,7-bis(dimethylhydroxysilyl)-9,9-diphenyldibenzosilole (M2), and ${ }^{13} \mathrm{C}$ NMR (100 MHz) spectra of (c) $\mathbf{M} 1$ and (d) $\mathbf{M} 2$ in $\left(\mathrm{CD}_{3}\right)_{2} \mathrm{SO}$ at ambient temperature. DMSO, dimethyl sulfoxide. 
a

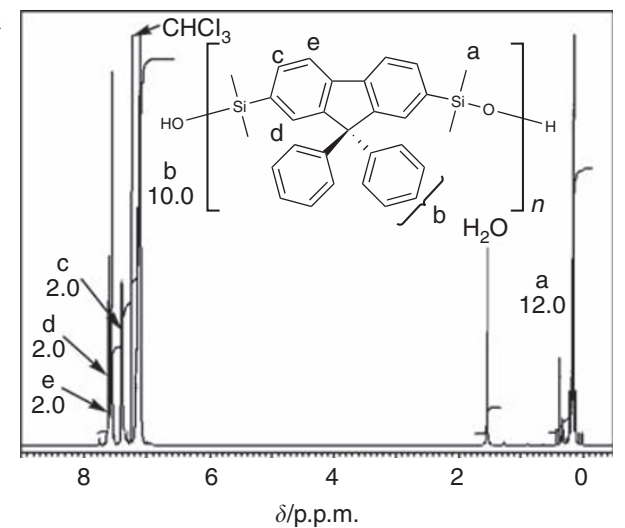

c

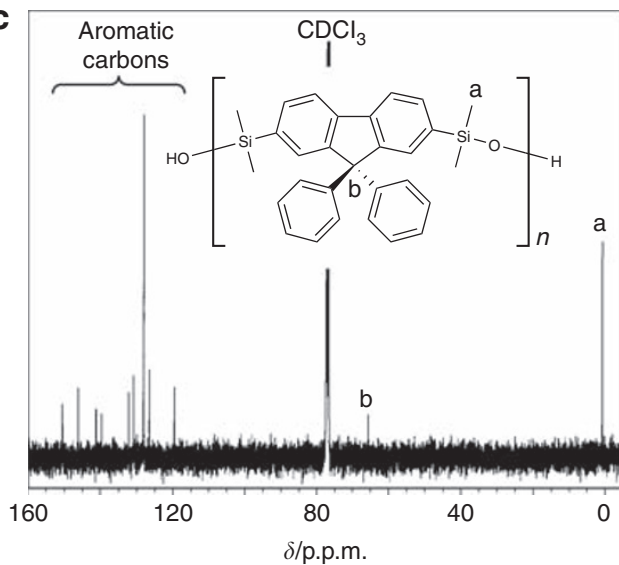

b

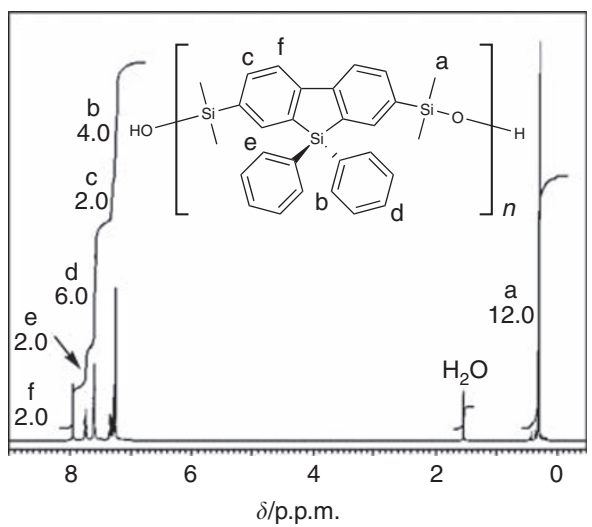

d

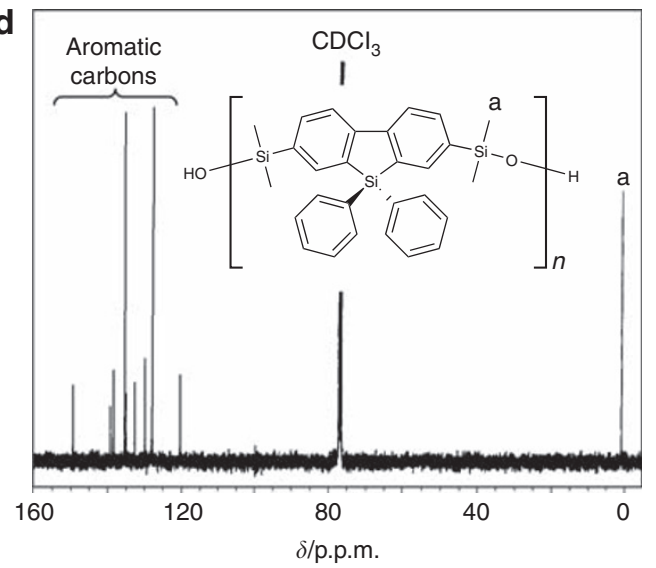

Figure $2{ }^{1} \mathrm{H}$ nuclear magnetic resonance (NMR; $400 \mathrm{MHz}$ ) spectra of (a) poly(tetramethyl-9,9-diphenyl-2,7-silfluorenylenesiloxane) (P1) and (b) poly(tetramethyl-9,9-diphenyl-2,7-sildibenzosilolylenesiloxane) (P2), and ${ }^{13} \mathrm{C} N M R(100 \mathrm{MHz})$ spectra of (c) $\mathbf{P} 1$ and (d) $\mathbf{P 2}$ in $\mathrm{CDCl}_{3}$ at ambient temperature.

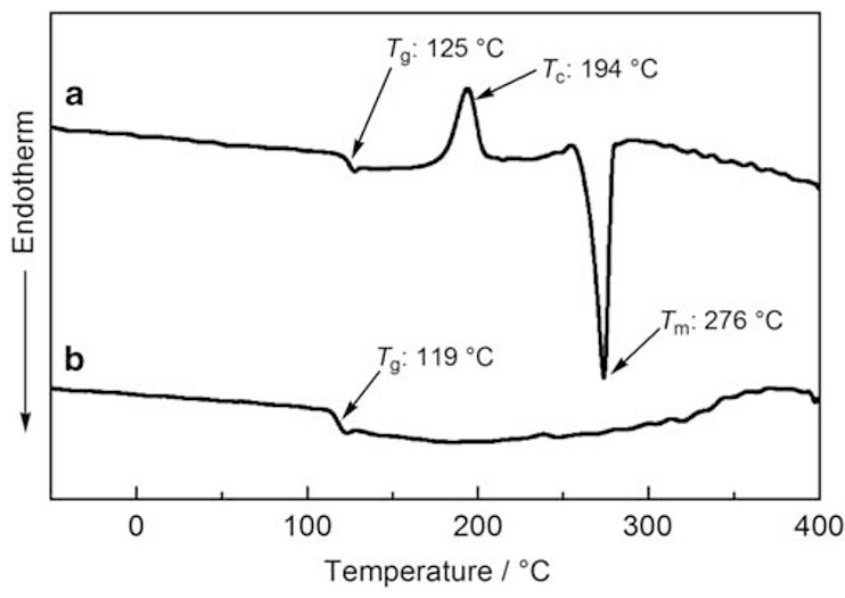

Figure 3 Differential scanning calorimetry traces of (a) poly(tetramethyl-9,9diphenyl-2,7-silfluorenylenesiloxane) (P1) and (b) poly(tetramethyl-9,9diphenyl-2,7-sildibenzosilolylenesiloxane) (P2) during a second heating scan at a heating rate of $10^{\circ} \mathrm{C} \mathrm{min}^{-1}$ under $\mathrm{N}_{2}$ flow rate of $10 \mathrm{ml} \mathrm{min}^{-1}$.

\section{RESULTS AND DISCUSSION}

\section{Synthesis of monomer and polymer}

Scheme 2 and Scheme 3 show the synthetic pathways for disilanol monomers, that is, $\mathbf{M} 1$ and $\mathbf{M} 2$, respectively.

M1 was obtained by the hydrolysis reaction catalyzed by $5 \%$ palladium on charcoal using 3. The hydrolysis of 6 to afford M2 was carried out using sodium ethoxide. ${ }^{25}$ We have attempted to obtain M2 by the hydrolysis reaction using 5\% palladium on charcoal as a manner similar to that used in the preparation of M1; however, the hydrolysis reaction hardly proceeded and the yield of M2 was extremely low plausibly because the dimerization reaction ${ }^{26}$ would be inclined to occur in the hydrolysis of 6 .

The obtained M1 and M2 underwent polycondensation using 1,1,3, 3-tetramethylguanidinium 2-ethylhexanoate as a catalyst to afford the corresponding poly(tetramethylsilarylenesiloxane) derivatives $\mathbf{P 1}$ and $\mathbf{P 2}$, respectively, as shown in Scheme 1. As reported previously, ${ }^{21,23}$ any solvents forming azeotropic mixtures with water and dissolving both monomer and the resulting polymer, such as benzene and toluene, can be used for the present polycondensation. The results of the polycondensation of $\mathbf{M} 1$ and $\mathbf{M} 2$ are summarized in Table 1.

P1 and P2 were obtained with good yields via polycondensation of M1 and M2, respectively, and exhibited good solubility in common organic solvents such as toluene, benzene, chloroform, dichloromethane and THF, although the rigid phenyl substituents were introduced at the 9-position of fluorene or dibenzosilole moiety.

The formation of P1 and P2 was confirmed by size-exclusion chromatography measurement and NMR spectroscopy. The sizeexclusion chromatography profiles of $\mathbf{P 1}$ and $\mathbf{P} \mathbf{2}$ indicated that the obtained polymers were unimodal and that the low-molecular weight species such as a cyclic dimer or trimer were almost completely removed by reprecipitation in methanol. The ${ }^{1} \mathrm{H}$ and ${ }^{13} \mathrm{C} N M R$ spectra of $\mathbf{M} 1$ and $\mathbf{M} 2$ are shown in Figure 1, and those of $\mathbf{P 1}$ and P2 are shown in Figure 2. 

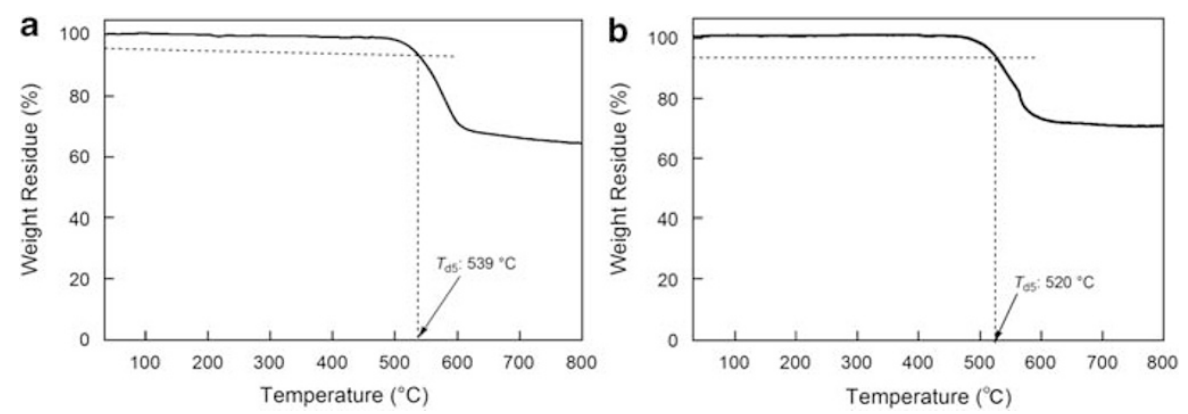

Figure 4 Thermogravimetry curves of (a) poly(tetramethyl-9,9-diphenyl-2,7-silfluorenylenesiloxane) (P1) and (b) poly(tetramethyl-9,9-diphenyl-2,7sildibenzosilolylenesiloxane) (P2) at heating rate of $10^{\circ} \mathrm{C} \mathrm{min}^{-1}$ in a nitrogen atmosphere.
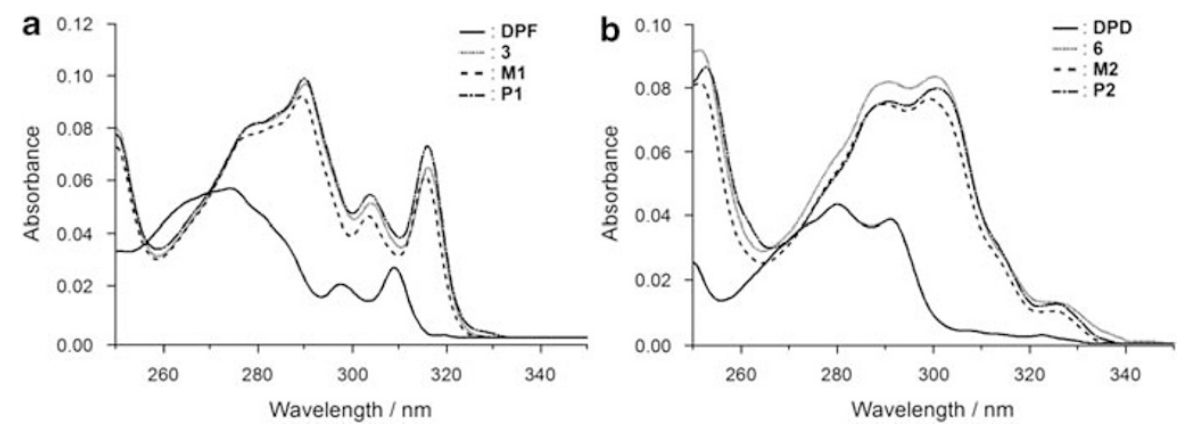

Figure 5 Absorption spectra of (a) diphenylfluorene and (b) diphenyldibenzosilole derivatives in $\mathrm{CHCl}_{3}$ solution (conc. $4.0 \times 10^{-6} \mathrm{~mol} \mathrm{I}^{-1}$ ). $\mathrm{DPF}$, 9,9-diphenylfluorene; DPD, 9,9-diphenyldibenzosilole; 3, 2,7-(dimethylsilyl)-9,9-diphenylfluorene; 6, 2,7-(dimethylsilyl)-9,9-diphenyldibenzosilole; M1, 2,7bis(dimethylhydroxysilyl)-9,9-diphenylfluorene; $\quad$ M2, 2,7-bis(dimethylhydroxysilyl)-9,9-diphenyldibenzosilole; $\quad$ P1, poly(tetramethyl-9,9-diphenyl-2,7silfluorenylenesiloxane); P2, poly(tetramethyl-9,9-diphenyl-2,7-sildibenzosilolylenesiloxane).
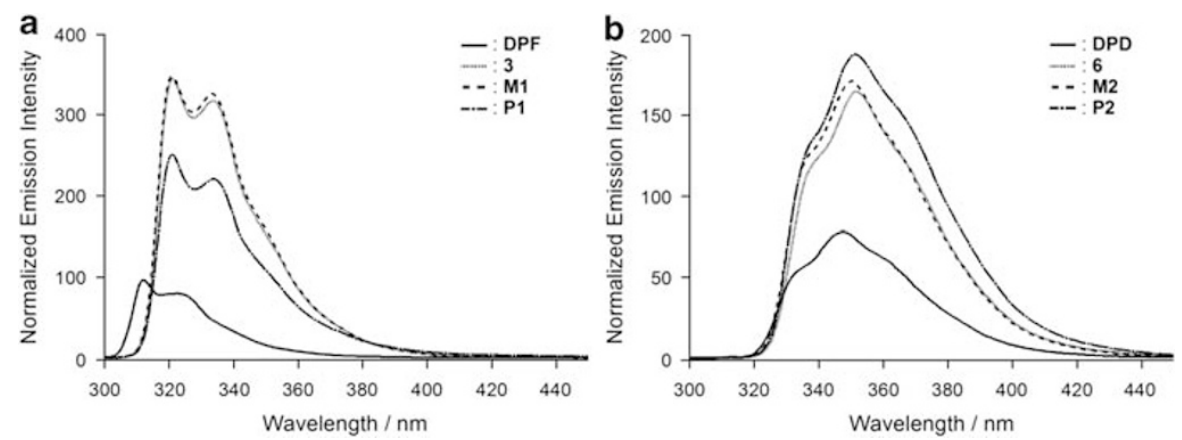

Figure 6 Fluorescence spectra of (a) diphenylfluorene and (b) diphenyldibenzosilole derivatives in $\mathrm{CHCl}_{3} \quad$ solution (conc. $4.0 \times 10^{-6} \mathrm{moll}^{-1}$, $\left.\lambda_{\text {ex }} ; 285 \mathrm{~nm}\right)$ at ambient temperature. The value of the vertical axis in the case of the fluorescence spectra was normalized using the molar extinction coefficient at $\lambda_{\text {ex: }} 285 \mathrm{~nm}$. DPF: 9,9-diphenylfluorene; DPD: 9,9-diphenyldibenzosilole; 3, 2,7-(dimethylsilyl)-9,9-diphenylfluorene; 6, 2,7-(dimethylsilyl)9,9-diphenyldibenzosilole; M1, 2,7-bis(dimethylhydroxysilyl)-9,9-diphenylfluorene; M2, 2,7-bis(dimethylhydroxysilyl)-9,9-diphenyldibenzosilole; P1, poly(tetramethyl-9,9-diphenyl-2,7-silfluorenylenesiloxane); P2, poly(tetramethyl-9,9-diphenyl-2,7-sildibenzosilolylenesiloxane).

The ${ }^{1} \mathrm{H}$ and ${ }^{13} \mathrm{C}$ NMR spectra of $\mathbf{P} \mathbf{1}$ and $\mathbf{P} 2$ were almost similar to those of $\mathbf{M} 1$ and $\mathbf{M} 2$, respectively, except the disappearance of a signal at 5.91 or 5.94 p.p.m. based on $-\mathrm{OH}$ groups as observed in the ${ }^{1} \mathrm{H}$ NMR spectrum of M1 or M2. The integrated ratio of each ${ }^{1} \mathrm{H}$ NMR signal was consistent with the structure of $\mathbf{P 1}$ and $\mathbf{P} \mathbf{2}$ as described in Figure 2. These results strongly support that no side-reactions occurred during polycondensation.

\section{Thermal characterization of polymer}

Table 1 also summarizes the thermal characterization of $\mathbf{P 1}$ and $\mathbf{P 2}$. Figure 3 depicts the DSC thermograms for $\mathbf{P} \mathbf{1}$ and $\mathbf{P} 2$ on a second heating scan.
The glass transition temperatures $\left(T_{\mathrm{g}} \mathrm{s}\right)$ of $\mathbf{P} \mathbf{1}$ and $\mathbf{P} \mathbf{2}$ were 125 and $119^{\circ} \mathrm{C}$, respectively, indicating no remarkable difference in $T_{\mathrm{g}}$ between $\mathbf{P} 1$ and $\mathbf{P 2}$. In the meantime, the melting temperature $\left(T_{\mathrm{m}}\right)$ of $\mathbf{P} \mathbf{1}$ was observed at $276^{\circ} \mathrm{C}$ after the exothermal crystallization at $194^{\circ} \mathrm{C}\left(T_{\mathrm{c}}\right.$ in Figure 3); however, neither $T_{\mathrm{m}}$ nor $T_{\mathrm{c}}$ was observed in the DSC thermogram of $\mathbf{P} 2$. This result indicates that $\mathbf{P} 1$ exhibits crystallinity, and the introduction of dibenzosilole moiety in the main chain decreased the crystallization tendency of polymer chains.

In addition, Figure 4 depicts the thermogravimetry curves for P1 and $\mathbf{P 2}$.

The $5 \%$ weight loss temperatures $\left(T_{\mathrm{d} 5} \mathrm{~s}\right)$ of $\mathbf{P 1}$ and $\mathbf{P 2}$ were determined to be 539 and $520^{\circ} \mathrm{C}$, respectively, indicating the excellent 
Table 2 Optical properties of diphenylfluorene and diphenyldibenzosilole derivatives

\begin{tabular}{|c|c|c|c|}
\hline Compound & $\lambda_{a b s} / n m\left(\varepsilon / / \mathrm{mol}^{-1} \mathrm{~cm}^{-1}\right)$ & $\lambda_{e m} / n m^{a}$ & $\Phi_{F}^{\mathrm{b}}$ \\
\hline \multirow[t]{3}{*}{ 9,9-diphenylfluorene } & $273(14300)$ & 310 & 0.04 \\
\hline & 297 (5500) & 323 & \\
\hline & 309 (7800) & & \\
\hline \multirow[t]{3}{*}{5} & 291 (25300) & 310 & 0.26 \\
\hline & $304(13500)$ & 321 & \\
\hline & $316(17800)$ & 334 & \\
\hline \multirow[t]{3}{*}{ M1 } & $290(24000)$ & 309 & 0.27 \\
\hline & $304(12300)$ & 320 & \\
\hline & $316(17000)$ & 333 & \\
\hline \multirow[t]{3}{*}{ P1 } & $290(25800)$ & 309 & 0.19 \\
\hline & $304(14300)$ & 321 & \\
\hline & $316(20000)$ & 334 & \\
\hline \multirow[t]{3}{*}{ 9,9-diphenyldibenzosilole } & $281(11000)$ & 348 & 0.06 \\
\hline & $292(10000)$ & & \\
\hline & $320(750)$ & & \\
\hline \multirow[t]{3}{*}{6} & $253(23800)$ & 352 & 0.19 \\
\hline & $300(21000)$ & & \\
\hline & 324 (3250) & & \\
\hline \multirow[t]{3}{*}{ M2 } & $252(21300)$ & 351 & 0.20 \\
\hline & $300(19000)$ & & \\
\hline & 324 (2500) & & \\
\hline \multirow[t]{3}{*}{ P2 } & $253(22300)$ & 352 & 0.23 \\
\hline & $300(20000)$ & & \\
\hline & $324(3000)$ & & \\
\hline
\end{tabular}

Abbreviations: 5, 2,7-bis(dimethylsilyl)-9,9-diphenylfluorene; 6, 2,7-bis(dimethylsilyl)-9,9diphenyldibenzosilole; M1, 2,7-bis(dimethylhydroxysilyl)-9,9-diphenylfluorene; M2, 2,7-bis(dimethylhydroxysilyl)-9,9-diphenyldibenzosilole; P1, poly(tetramethyl-9,9-diphenyl-2,7silfluorenylenesiloxane); P2, poly(tetramethyl-9,9-diphenyl-2,7-sildibenzosilolylenesiloxane). ${ }^{a}$ Excited at $285 \mathrm{mn}$. The concentration was fixed at $4.0 \times 10^{-6} \mathrm{~mol} \mathrm{I}^{-1}$ as diphenylfluorene or diphenyldibenzosilole unit.

bFluorescence quantum yields $\left(\Phi_{\mathrm{F}}\right)$ of diphenyldibenzosilole and diphenylfluorene derivatives were measured in $\mathrm{CHCl}_{3}$ using a HAMAMATSU PHOTONICS absolute PL quantum yield measurement system C9920-02 $\left(\lambda_{\mathrm{ex}}=285 \mathrm{~nm}\right) .^{24}$

thermal stabilities of P1 and P2. Poly(tetramethyl-9,9-dimethyl-2,7silfluorenylenesiloxane $)^{21}$ has been reported to show a $T_{\mathrm{g}}$ of $67^{\circ} \mathrm{C}$ and $T_{\mathrm{d} 5}$ of $464^{\circ} \mathrm{C}$; therefore, the introduction of bulky and rigid phenyl substituents onto a fluorene or dibenzosilole skeleton turned out to be effective in the improvement of thermal stability.

\section{Optical properties}

Fluorene-based conjugated polymers have attracted much attention in the field of OLEDs in recent years as mentioned above. Dibenzosilolebased conjugated polymers have also been expected to be new materials for the substitution of fluorene-based conjugated polymers. Therefore, we investigated the optical properties of the obtained diphenylfluorene and diphenyldibenzosilole derivatives, including both monomers and polymers. The absorption and fluorescence spectra of diphenylfluorene and diphenyldibenzosilole derivatives are shown in Figures 5 and 6, respectively.

Table 2 summarizes the optical properties of diphenylfluorene and diphenyldibenzosilole derivatives.

In all present absorption spectra, bathochromic and hyperchromic effects were observed after the introduction of silylene groups onto diphenylfluorene and diphenyldibenzosilole skeletons, presumably because of $\sigma-\pi$ and $\sigma^{*}-\pi^{*}$ conjugations between the silylene groups and aromatic moieties. ${ }^{12-17}$ The bathochromic effect has been known to be induced by lowering the energy gap between the highest occupied molecular orbital (HOMO) and lowest unoccupied molecular orbital (LUMO) states because of destabilization of the HOMO state through $\sigma-\pi$ conjugation and stabilization of the LUMO state through $\sigma^{\star}-\pi^{\star}$ conjugation. The hyperchromic effects result from the enhancement of the transition moment based on the increase in the dipole moments of the HOMO and LUMO states owing to the $\sigma-\pi$ conjugation in the HOMO and the $\sigma^{*}-\pi^{*}$ conjugation in the LUMO. ${ }^{12-17}$

On the other hand, the $0-0$ electronic transition was observed at around $316 \mathrm{~nm}$ in the case of silyl-substituted diphenylfluorene derivatives (5, M1 and P1), as shown in Figure 5a, whereas it was observed at around $324 \mathrm{~nm}$ in the case of silyl-substituted diphenyldibenzosilole derivatives (6, M2, and P2), as shown in Figure 5b. This bathochromic shift would be due to the stabilization of the LUMO state through $\sigma^{*}-\pi^{*}$ conjugation induced by the replacement of the C-9 carbon in fluorene by silicon. In addition, the absorbance of the $0-0$ electronic transition band in the case of silyl-substituted diphenylfluorene derivatives was larger than that of the vibronic band at around $304 \mathrm{~nm}$; meanwhile, the absorbance of the $0-0$ electronic transition band in the case of silyl-substituted diphenyldibenzosilole derivatives was smaller than that of the vibronic band at around $313 \mathrm{~nm}$ as a shoulder peak. This finding suggests that the molecular structure in the $S_{1}$ state for silyl-substituted diphenyldibenzosilole derivatives tends to change. Differences in the shape of the absorption and fluorescence spectra between a series of diphenylfluorene derivatives and those of diphenyldibenzosilole ones are as shown in Figures 5 and 6, that is, the relatively structureless shapes of the absorption and fluorescence spectra of a series of dibenzosilole derivatives were observed. This result also suggests the difference in the tendency for change of molecular structure in the $S_{1}$ state between diphenylfluorene and diphenyldibenzosilole derivatives.

In addition, the fluorescence quantum yield $\left(\Phi_{\mathrm{F}}\right)$ was improved by the introduction of silylene groups into aromatic moieties for both diphenylfluorene and diphenyldibenzosilole derivatives. The $\Phi_{\mathrm{F}}$ of P1 was lower than that of M1, probably because the crystallization tendency in $\mathbf{P 1}$ results in a relatively strong interaction between the diphenylfluorene units in P1 that leads to the aggregation of diphenylfluorene units. In addition, the concentration of diphenylfluorene units was so low $\left(4.0 \times 10^{-6} \mathrm{moll}^{-1}\right.$ as diphenylfluorene unit) that the aggregate formation may occur through the intramolecular interactions between the diphenylfluorene units. On the other hand, the fluorescence quantum yield of $\mathbf{P} 2$ was higher than that of M2, indicating a decrease in the tendency to aggregate using a dibenzosilole skeleton. This result may also be supported by the observation that the introduction of dibenzosilole moiety in the main chain decreases the crystallization tendency of polymer chains. The use of dibenzosilole skeletons was confirmed to be effective in the inhibition of aggregate formation and to result in improved emission intensity.

\section{CONCLUSION}

The syntheses of poly(tetramethylsilarylenesiloxane) derivatives with diphenylfluorene and diphenyldibenzosilole moieties were achieved. P1 and P2 exhibited good solubility in common organic solvents such as benzene, toluene, chloroform, dichloromethane and THF. There was no significant difference in $T_{\mathrm{g}}$ between $\mathbf{P} \mathbf{1}$ and $\mathbf{P} 2$; however, the $T_{\mathrm{m}}$ of $\mathbf{P} \mathbf{1}$ was observed in spite of the absence of $T_{\mathrm{m}}$ in the case of $\mathbf{P} \mathbf{2}$, indicating that the introduction of a dibenzosilole moiety in the main chain decreased the crystallization tendency of polymer chains. The $T_{\mathrm{d} 5} \mathrm{~s}$ of $\mathbf{P} 1$ and $\mathbf{P} 2$ were 539 and $520{ }^{\circ} \mathrm{C}$, respectively, suggesting the excellent thermostability of $\mathbf{P} \mathbf{1}$ and $\mathbf{P} \mathbf{2}$. As for the optical properties of the obtained diphenylfluorene and diphenyldibenzosilole derivatives, the bathochromic and hyperchromic effects were observed 
by introducing dimethylsilyl substituents onto diphenylfluorene and diphenyldibenzosilole skeletons in both the absorption and the fluorescence spectra. The fluorescence quantum yield of P1 was lower than that of M1 probably because of the formation of aggregates; however, the fluorescence quantum yield of $\mathbf{P} 2$ was higher than that of $\mathbf{M} 2$, indicating a decrease in the tendency to aggregate using a dibenzosilole skeleton.

\section{ACKNOWLEDGEMENTS}

This work was partly supported by the Japan Science and Technology Agency through Research for Promoting Technological Seeds 2009 (No. 03-072). We would like to express our appreciation to Dr Yasushi Numata, College of Engineering, Nihon University, for the helpful discussion about optical properties; Ms Satoko Tokiwa and Ms Nami Sugashima, Nihon University College of Engineering Worldwide Research Center for Advanced Engineering and Technology (NEWCAT), for performing NMR measurements and Dr Miki Hasegawa, School of Science and Engineering, Aoyama Gakuin University, for performing the fluorescence quantum yield measurement.

1 Andrew, C. G. \& Klaus, M. Polyphenylene-type emissive materials: poly(para-phenylene)s, polyfluorenes, and ladder polymers. Adv. Polym. Sci. 199, 1-82 (2006).

2 Leclerc, M. Polyfluorenes: twenty years of progress. J. Polym. Sci., Part A: Polym. Chem. 39, 2867-2873 (2001)

3 Neher, D. Polyfluorene homopolymers: conjugated liquid-crystalline polymers for bright blue emission and polarized electroluminescence. Macromol. Rapid Commun. 22, 1365-1385 (2001).

4 Scherf, U. \& List, E. J. W. Semiconducting polyfluorenes: towards reliable structureproperty relationship. Adv. Mater. 14, 477-487 (2002).

5 Gaal, M., List, E. J. W. \& Scherf, U. Excimer or emissive on-chain defects? Macromolecles 36, 4236-4237 (2003)

6 List, E. J. W., Guentner, R., Guentner, R., Scanducci de, F. P. \& Scherf, U. The effect of keto defect sites on the emission properties of polyfluorene-type materials. Adv. Mater. 14, 374-378 (2002).

7 Cho, S. Y., Grimsdale, A. C., Jones, D. J., Watkins, S. E. \& Holmes, A. B. Polyfluorenes without monoalkylfluorene defects. J. Am. Chem. Soc. 129, 11910-11911 (2007).

8 Trimpin, S., Grimsdale, A. C., Räder, H. J. \& Müllen, K. Characterization of an insoluble poly(9,9-diphenyl-2,7-fluorene) by solvent-free sample preparation for MALDI-TOF mass spectrometry. Anal. Chem. 74, 3777-3782 (2002).
9 Chan, K. L., McKiernan, M. J., Towns, C. R. \& Holmes, A. B. Poly(2,7-dibenzosilole): a blue light emitting polymer. J. Am. Chem. Soc. 127, 7662-7663 (2005).

10 Wong, W. W. H. \& Holmes, A. B. Poly(dibenzosilole)s. Adv. Polym. Sci. 212, 85-98 (2008).

11 Yamaguchi, S., Endo, T., Uchida, M., Izumizawa, T., Furukawa, K. \& Tamao, K. Toward new materials for organic electroluminescent devices: synthesis, structures, and properties of a series of 2,5-diaryl-3,4-diphenylsiloles. Chem. Eur. J. 6, 1683-1692 (2000).

12 Shizuka, H., Sato, Y., Ueki, Y., Ishikawa, M. \& Kumada, M. The $2 \mathrm{p} \pi^{*}-3 \mathrm{~d} \pi$ interaction in aromatic silanes. Fluorescence from the ${ }^{1}(2 p \pi, 3 d \pi)$ intramolecular charge-transfer state. J. Chem. Soc., Faraday Trans. 1 80, 341-357 (1984).

13 Declercq, D., Delbeke, P., De Schryver, F. C., Van Meervelt, L. \& Miller, R. D. Groundand excited-state interaction in di-1-pyrenyl substituted oligosilanes. J. Am. Chem. Soc. 115, 5702-5708 (1993).

14 Kyushin, S., Ikuragi, M., Goto, M., Hiratsuka, H. \& Matsumoto, H. Synthesis and electronic properties of 9,10-disilylanthracenes. Organometallics 15, 1067-1070 (1996).

15 Maeda, H. Inoue, Y., Ishida, H. \& Mizuno, K. UV absorption and fluorescence properties of pyrene derivatives having trimethylsilyl, trimethylgermyl, and trimethylstannyl groups. Chem. Lett. 30, 1224-1225 (2001).

16 Imai, K., Sasaki, T., Abe, J., Kimoto, A., Tamai, Y. \& Nemoto, N. Synthesis of nove poly(tetramethyl-2,7-silpyrenylenesiloxane) and its thermal and optical properties. Polym. J. 41, 584-585 (2009).

17 Imai, K., Hatano, S., Kimoto, A., Abe, J., Tamai, Y. \& Nemoto, N. Optical and electronic properties of siloxane-bridged cyclic dimers with naphthylene or pyrenylene moieties. Tetrahedron 66, 8012-8017 (2010).

18 Kitamura, N. \& Yamamoto, T. Carbon-silicon coupling between fluorenyl Grignard reagents and dichlorosilanes for synthesis of novel copolymers and chemical properties of the copolymers. Appl. Organomet. Chem. 17, 840-842 (2003).

19 Mark, J. E. in Silicon-Based Polymer Science (ed. Ziegler, J.M. \& Gordon, F.W.), Ch. 2 47-68 (American Chemical Society, 1990).

20 Brook, M. A. Silicon in Organic, Organometallic, and Polymer Chemistry 256-308 (John Wiley \& Sons, Inc, New York, 2000).

21 Nemoto, N., Yamaguchi, T., Ozawa, Y., Nigorikawa, M., Yanai, Y. \& Nagase, Y. Synthesis and thermal characterization of novel fluorene-based polysiloxane derivatives. Polym. Bull. 61, 165-175 (2008).

22 Wong, K.- T., Wang, Z.- J., Chien, Y.- Y. \& Wang, C.- L. Synthesis and properties of 9,9diarylfluorene-based triaryldiamines. Org. Lett. 3, 2285-2288 (2001).

23 Otomo, Y., Nagase, Y. \& Nemoto, N. Synthesis and properties of novel poly(tetramethylsilnaphthylenesiloxane) derivatives. Polymer 46, 9714-9724 (2005).

24 Kawamura, Y., Sasabe, H. \& Adachi, C. Simple accurate system for measuring absolute photoluminescence quantum efficiency in organic solid-state thin films. Jpn. J. Appl. Phys. 43, 7729-7730 (2004).

25 Merker, R. L. \& Scott, M. J. Preparation and properties of poly(tetramethyl-p-silphenylene-siloxane). J. Polym. Sci.: Part A 2, 15-29 (1964).

26 Barnes Jr, G. H. \& Daughenbaugh, N. E. The preparation of organosilanols via the metal-catalyzed reaction of organosilicon hydrides with water. J. Org. Chem. 31, 885-887 (1966). 